\title{
Effect of smoking on attack rates of pulmonary and pleural lesions related to exposure to asbestos dust
}

\author{
G H G McMillan, R J PETHYBRIDGE, AND G SHEERS \\ From the Medical Research Unit, HM Naval Base, Devonport, Plymouth, UK
}

ABSTRACT In follow-up studies of samples of employees at two of Her Majesty's Dockyards the prevalence of asbestos-related lesions in smokers and ex-smokers was statistically significantly higher than in non-smokers even when differences in age and exposure risk were considered.

\begin{abstract}
Many men who have been exposed to asbestos dust at work are concerned about the effects this may have on their health and wish to know the risk of developing an asbestos-related disease. Most of those found at routine health screening in HM Dockyards to have pleural plaques or diffuse pleural thickening ask this directly. To assist those responsible for their health care to answer these questions more factually the Ministry of Defence (Navy) and the Medical Research Council collaborated in a series of epidemiological surveys to examine the relation between the attack rate of asbestos-related lesions and smoking habit.*
\end{abstract}

\section{Methods}

In 1966 and $196810 \%$ random samples of all male civilian employees at HM Dockyards at Devonport and Portsmouth respectively were studied to determine the prevalence of asbestos-related pulmonary and pleural lesions. ${ }^{12}$ The exposure of the population to asbestos was described by Harries, ${ }^{3}$ and no man should have been exposed at work since 1970. The 1414 men at Devonport and 1009 men at Portsmouth who responded in these initial surveys were studied in 1977 to determine rates of attack of asbestos-related lesions.

EXAMINATION

Responders completed a questionnaire to update smoking and occupational histories. Dockyard and other records were examined to obtain occupational

*Full details of the studies may be obtained from Surgeon Lt-Cdr G H G McMillan, Medical Research Unit, 1 East Avenue, HM Naval Base, Devonport, Plymouth.

Received 15 October 1979

Accepted 30 November 1979 details of the non-responders. Those still living in the geographical areas of the dockyards attended for chest radiography. In 1966 and 1968 the initial screening radiograph was the $100 \times 100 \mathrm{~mm}$ photofluorograph produced by the Odelca camera coupled to a $200 \mathrm{~mA} x$-ray generator and phototimer. Men were recalled for full-size films if an abnormality was suspected on the $100-\mathrm{mm}$ film. During the resurvey the same equipment, film type, and staff were used to obtain $100-\mathrm{mm}$ films. A full-size chest radiograph was taken at the same visit to reduce the false-positive recall rate. Men living remote from the dockyard areas had full-size posterioanterior (PA) and both anterior-oblique views taken at their local hospital.

All the $100-\mathrm{mm}$ radiographs and the full-size PA radiographs of those living away from dockyard areas were read independently by two of us (GHGM and GS), using the criteria adopted in the original surveys. Abnormalities seen on these full-size PA radiographs were recorded for survey purposes only when it was considered that these would have been detected on a $100-\mathrm{mm}$ film. All the radiographs bore an identifying number only and thus were read in ignorance of the subject's identity, occupation, asbestos exposure, clinical findings, age, smoking habit, and previous diagnoses.

When either reader suspected an abnormality on these screening films the full-size PA radiograph was read by both readers together, and if this confirmed or did not fully dismiss the suspicion the man was recalled for further radiography if satisfactory anterior-oblique views were not available. Whenever parenchymal fibrosis was suspected the man was recalled for further questioning, full clinical examination, and pulmonary function tests. A very low threshold of suspicion was maintained in selecting 
cases for further examination. Asbestos-related lesions were finally diagnosed after considering the findings at that examination but without considering smoking habit.

\section{CLASSIFICATION OF ASBESTOS-RELATED LESIONS}

Adequate evidence from the occupational history of exposure to asbestos was essential to the diagnosis in all cases. The abnormalities were classified as uncalcified pleural plaques, calcified pleural plaques, diffuse pleural thickening, and parenchymal fibrosis. Both readers were required to agree on the final classification.

Pleural plaques are discrete areas of pleural thickening characteristically bilateral; they may be calcified. These were diagnosed only when they could be clearly differentiated from other soft tissue shadows and in the absence of evidence of previous trauma at or near the site. Diffuse pleural thickening is often bilateral and has an indistinct outline becoming progressively more faint towards the centre of the lung field. It often affects the costophrenic angle and was diagnosed only in the absence of a history of infection, surgery, or haemothorax.

The diagnosis of parenchymal fibrosis was accepted only when there was the typical radiographic appearance of irregular small opacities together with persistent basal crackles and a restrictive ventilatory defect with reduced gas transfer factor. The subject's smoking habit was known to the examining doctor before the chest was auscultated and the results of pulmonary function tests examined.

\section{SMOKING HABIT}

All subjects who responded to the questionnaire were classified as non-smokers, smokers, or exsmokers from the information available from the previous and current questionnaire. The validity of this method was assessed by comparing the postal questionnaire responses of those recalled for clinical examination with the responses given at that examination. Only minimal variation, which would not have resulted in the subject being erroneously classified, was found. Smoking was defined as at least one cigarette (or alternative tobacco equivalent) smoked a day for at least one year. A non-smoker had never smoked, a smoker smoked currently, and an ex-smoker had ceased smoking for at least a year.

\section{ASSESSMENT OF EXPOSURE}

As no exposure records were available each man was allocated by occupation to one of four asbestos exposure groups in descending order of risk of heavy exposure.

Group 1-Lagger, asbestos sprayer, sailmaker lagger, asbestos storeman, and painter afloat.

Group 2-Electrical fitter, caulker, coppersmith, shipfitter, boilermaker, driller, welder, burner, joiner, and plumber.

Group 3-Shipwright and mechanical fitter.

Group 4-All other occupations.

Men employed in various occupations or grades over the years were allocated by the occupation with the highest risk of exposure. This method differs from that used in reports of the initial surveys. All exposure group related rates in this paper are based on the reclassification.

Although stringent measures to prevent the exposure of employees to asbestos dust were introduced in the dockyards in 1966, the effect was not immediate, and we consider that, while the risk of exposure diminished year by year, full protection was probably not achieved until 1970. Therefore we have used that year as the end point of all exposure for the men in this study.

\section{Results}

\section{RESPONSE}

Only two of the 1414 Devonport and three of the 1009 Portsmouth men examined in 1966 and 1968 could not be traced in 1977. At Devonport 1012 men $(71.6 \%$ of the personnel examined in 1966, $81.2 \%$ of survivors) and 719 men at Portsmouth

Table 1 Total number of men, deaths, and response rates in exposure groups at Devonport and Portsmouth

\begin{tabular}{|c|c|c|c|c|c|}
\hline & \multirow[t]{2}{*}{$A l l$} & \multicolumn{4}{|c|}{ Exposure group } \\
\hline & & 1 & 2 & 3 & 4 \\
\hline \multicolumn{6}{|c|}{ Devonport } \\
\hline Total in 1977 sample & 1414 & 51 & 486 & 333 & 544 \\
\hline No $(\%)$ dead by 1977 & $168(11.9)$ & $8(15 \cdot 7)$ & $40(8 \cdot 2)$ & $23(6 \cdot 9)$ & $97(17 \cdot 8)$ \\
\hline No attended for radiograph & 1012 & 41 & 366 & 261 & 344 \\
\hline$\%$ survivors attended & $81 \cdot 2$ & $95 \cdot 4$ & $82 \cdot 1$ & $84 \cdot 2$ & $77 \cdot 0$ \\
\hline \multicolumn{6}{|c|}{ Portsmouth } \\
\hline Total in 1977 sample & 1009 & 49 & 272 & 255 & 433 \\
\hline No $(\%)$ dead by 1977 & $88(8 \cdot 7)$ & $4(8 \cdot 2)$ & $21(7 \cdot 7)$ & $12(4 \cdot 7)$ & $51(11 \cdot 8)$ \\
\hline No attended for radiograph & 719 & 39 & 203 & 190 & 287 \\
\hline$\%$ survivors attended & $78 \cdot 1$ & $86 \cdot 7$ & $80 \cdot 9$ & $78 \cdot 2$ & $75 \cdot 1$ \\
\hline
\end{tabular}


(71.3\% of those seen in $1968,78.1 \%$ of survivors) were re-examined in 1977 (table 1). Response rates decreased through the exposure groups in order of reducing risk, both dockyards presenting a similar pattern. Figure 1 shows time since first potential exposure to asbestos at work of the survivors. Response rates were slightly lower in those men with either shortest or longest time since first exposure (fig 2).

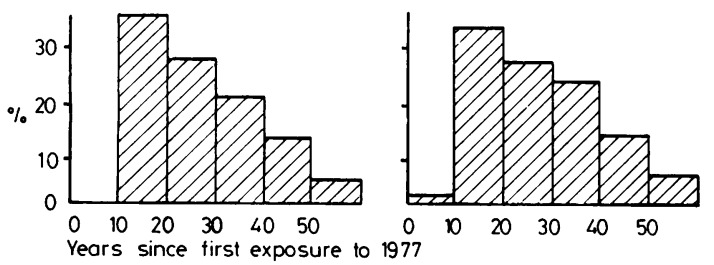

Fig 1 Relative frequency distribution of time since first exposure to asbestos at work to 1977 of survivors at Devonport and Portsmouth.

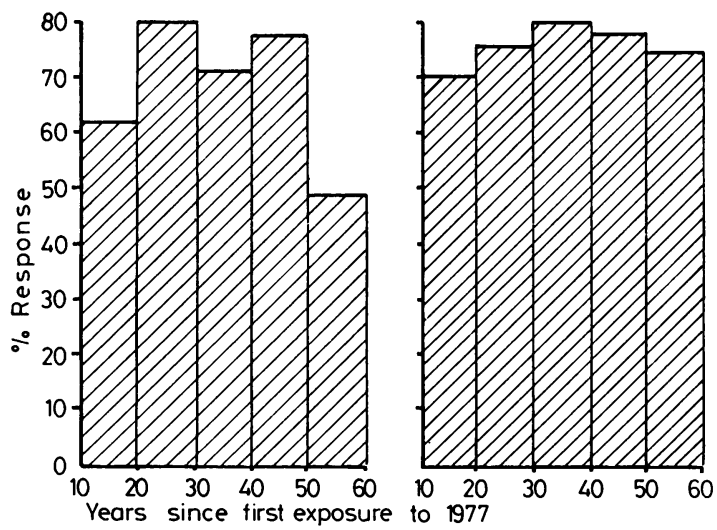

Fig 2 Response rates (\%) among survivors related to time since first exposure at Devonport and Portsmouth.
PREVALENCE OF LESIONS IN ALL MEN

RE-EXAMINED IN 1977

The overall prevalence of asbestos-related lesions was $13.6 \%$ at Devonport $(4.1 \%$ for the same men in $1966)$ and $13.1 \%$ at Portsmouth $(2.8 \%$ in 1968$)$. The rate decreases with reducing exposure risk in both dockyards (table 2) from a group 1 rate that is appreciably higher than the other groups. This relation is particularly pronounced for parenchymal fibrosis, although only one-third of these cases is in group 1.

Although not presented here, age (which largely reflects time in occupation) is also a factor positively influencing the prevalence rates. ${ }^{4}{ }^{5}$ Differences in the prevalence rate among the groups are likely to be partly attributable to the differences in age distribution, group 1 having a higher proportion of older men with correspondingly longer exposure periods.

\section{EFFECTS OF SMOKING ON THE}

PREVALENCE OF ASBESTOS LESIONS

In both dockyards the prevalence rates for asbestosrelated lesions in smokers and ex-smokers are higher than that for non-smokers in all but one exposure group (Portsmouth 3) (table 3). Some rates are based on small numbers and should accordingly be treated with some caution. As noted previously, age and occupational-exposure risk influence prevalence rates; thus we have assessed whether the influence of smoking is negligible after allowance has been made for these factors. Table 4 presents a summary of the actual "lesion" cases found and the "expected" number assuming no influence due to smoking. Expected numbers are given to the nearest whole number, although statistical tests have been based on the "precise" expected numbers. Two sets of expected numbers and rates have been calculated; in the first set adjustments for exposure risk and age have been considered while in the second set no adjustments have been made.

Table 2 Number (and prevalence \%) of asbestos-related lesions in each exposure group for all responders in 1977

\begin{tabular}{|c|c|c|c|c|c|c|c|}
\hline \multirow{2}{*}{$\begin{array}{l}\text { Exposure } \\
\text { group }\end{array}$} & \multirow{2}{*}{$\begin{array}{l}\text { No } \\
\text { examined }\end{array}$} & \multicolumn{6}{|c|}{ No (and prevalence \%) with asbestos-related lesions in 1977} \\
\hline & & All types & Uncalcified plaques & Calcified plaques & $\begin{array}{l}\text { Diffuse pleural } \\
\text { thickening }\end{array}$ & $\begin{array}{l}\text { Parenchymal } \\
\text { fibrosis }\end{array}$ & Mesothelioma \\
\hline \multicolumn{8}{|c|}{ Devonport } \\
\hline 1 & 41 & $20(48 \cdot 8)$ & $12(29 \cdot 3)$ & $3(7 \cdot 3)$ & $1(2 \cdot 4)$ & $4(9 \cdot 8)$ & \\
\hline 2 & 366 & $49(13.4)$ & $28(7 \cdot 7)$ & $11(3.0)$ & $5(1.4)$ & $4(1 \cdot 1)$ & $1(0 \cdot 3)$ \\
\hline 3 & 261 & $34(13.0)$ & $19 \quad(7 \cdot 3)$ & $10(3 \cdot 8)$ & $3(1 \cdot 1)$ & $2(0 \cdot 8)$ & \\
\hline 4 & 344 & $35(10 \cdot 2)$ & $19(5.5)$ & $9(2 \cdot 6)$ & $5(1.5)$ & $2(0 \cdot 6)$ & \\
\hline All & 1012 & $138(13.6)$ & $78 \quad(7 \cdot 7)$ & $33(3 \cdot 3)$ & $14(1 \cdot 4)$ & $12(1 \cdot 2)$ & $1(0 \cdot 1)$ \\
\hline \multicolumn{8}{|c|}{ Portsmouth } \\
\hline 1 & 39 & $9(23 \cdot 1)$ & $2(5 \cdot 1)$ & $3(7 \cdot 7)$ & $2(5 \cdot 1)$ & $2(5 \cdot 1)$ & \\
\hline 2 & 203 & $34(16 \cdot 8)$ & $19(9 \cdot 4)$ & $10(4 \cdot 9)$ & $4(2 \cdot 0)$ & $1(0 \cdot 5)$ & \\
\hline 3 & 190 & $26(13 \cdot 7)$ & $12(6 \cdot 3)$ & $3(1 \cdot 6)$ & $8(4 \cdot 2)$ & $3(1 \cdot 6)$ & \\
\hline 4 & 287 & $25 \quad(8.7)$ & $17 \quad(5.9)$ & $7(2 \cdot 4)$ & $1(0 \cdot 3)$ & $0(0.0)$ & \\
\hline All & 719 & $94(13 \cdot 1)$ & $50 \quad(6.9)$ & $23(3 \cdot 2)$ & $15(2 \cdot 1)$ & $6(0.8)$ & \\
\hline
\end{tabular}


Table 3 Prevalence \% rates for asbestos-related lesions related to smoking habit (and number of men in each smoking category) for all responders at Devonport and Portsmouth in 1977

\begin{tabular}{|c|c|c|c|}
\hline \multirow{2}{*}{$\begin{array}{l}\text { Exposure } \\
\text { group }\end{array}$} & \multicolumn{3}{|c|}{ Prevalence $\%$ asbestos-related lesions. (No men in subgroup) } \\
\hline & Non-smokers & Smokers & Ex-smokers \\
\hline \multicolumn{4}{|c|}{ Devonport } \\
\hline 1 & $17 \quad(6)$ & 63 (19) & 44 (16) \\
\hline 2 & 7 (86) & 17 (165) & $13(115)$ \\
\hline 3 & $3(78)$ & $20(112)$ & 14 (71) \\
\hline 4 & $8(52)$ & 9 (193) & 13 (99) \\
\hline All & $6(222)$ & $16(489)$ & $15(301)$ \\
\hline \multicolumn{4}{|c|}{ Portsmouth } \\
\hline 1 & $0 \quad(8)$ & $20 \quad(20)$ & 45 (11) \\
\hline 2 & 8 (49) & $19(98)$ & 20 (56) \\
\hline 3 & 15 (48) & $15(82)$ & $12(60)$ \\
\hline 4 & 3 (58) & $7(150)$ & 15 (79) \\
\hline All & $8(163)$ & $13(350)$ & 17 (206) \\
\hline
\end{tabular}

Table 4 Number of men-observed and expected-with non-malignant asbestos-related lesions in each smoking category for Devonport and Portsmouth in 1977

\begin{tabular}{|c|c|c|c|}
\hline & Non-smokers & Smokers & Ex-smokers \\
\hline \multicolumn{4}{|c|}{ Devonport } \\
\hline No of men examined & 222 & 489 & 301 \\
\hline $\begin{array}{l}\text { Adjusted for exposure and age } \\
\text { Not adjusted for exposure and age }\end{array}$ & $\begin{array}{l}22(10 \cdot 1 \%) \\
30(13 \cdot 5 \%)\end{array}$ & $\begin{array}{l}68(14.0 \%) \\
66(13.5 \%)\end{array}$ & $\begin{array}{l}47(15 \cdot 7 \%) \\
41(13.5 \%)\end{array}$ \\
\hline \multicolumn{4}{|c|}{ Portsmouth } \\
\hline $\begin{array}{l}\text { No of men examined } \\
\text { No (and \%) of men with asbestos-related lesions } \\
\text { No (and \%) of men expected to have asbestos-related } \\
\text { lesions: }\end{array}$ & $163(8.0 \%)$ & $\begin{array}{l}350 \\
46(13 \cdot 1 \%)\end{array}$ & $35(17 \cdot 0 \%)$ \\
\hline $\begin{array}{l}\text { Adjusted for exposure and age } \\
\text { Not adjusted for exposure and age }\end{array}$ & $\begin{array}{l}18(10.9 \%) \\
21(13 \cdot 1 \%)\end{array}$ & $\begin{array}{l}45(12 \cdot 9 \%) \\
46(13 \cdot 1 \%)\end{array}$ & $\begin{array}{l}31(15 \cdot 2 \%) \\
27(13 \cdot 1 \%)\end{array}$ \\
\hline
\end{tabular}

Particularly for Devonport the two sets of expected lesion rates differ, indicating that exposure risk and age assert some influence on prevalence rates. The non-smokers in both dockyards have observed rates below the expected, and Devonport smokers and Portsmouth ex-smokers have rates above the expected. The Devonport observed rates are found to differ significantly from expectation (Goodness of fit test yields $\left.\chi^{2}=6.56, \mathrm{df}=2, \mathrm{p}<0.05\right)$ smoking had positively influenced the prevalence rates. The Portsmouth data suggest a similar conclusion, but the differences between the observed and expected rates are not significant. The relation between smoking habit and prevalence is maintained when the various lesions are considered separately (table 5). All subjects who developed parenchymal fibrosis were, or had been, smokers.

Table 5 Number of men in each smoking-habit category with each type of non-malignant asbestos-related lesion in 1977

\begin{tabular}{|c|c|c|c|}
\hline Lesion & Non-smokers & Smokers & Ex-smokers \\
\hline \multicolumn{4}{|c|}{ Devonport } \\
\hline Uncalcified plaques & 10 & 41 & 27 \\
\hline Calcified plaques & 3 & 19 & 11 \\
\hline Diffuse pleural thickening & 0 & 13 & 1 \\
\hline Parenchymal fibrosis & $\mathbf{0}$ & 6 & 6 \\
\hline All types & 13 & 79 & 45 \\
\hline No of men & 222 & 489 & 301 \\
\hline Prevalence $\%$ & $5 \cdot 9$ & $16 \cdot 2$ & $15 \cdot 0$ \\
\hline \multicolumn{4}{|c|}{ Portsmouth } \\
\hline Uncalcified plaques & 9 & 24 & 17 \\
\hline Calcified plaques & 3 & 10 & 10 \\
\hline Diffuse pleural thickening & 1 & 8 & 6 \\
\hline Parenchymal fibrosis & 0 & 4 & 2 \\
\hline All types & 13 & 46 & 35 \\
\hline No of men & 163 & 350 & 206 \\
\hline Prevalence $\%$ & $8 \cdot 0$ & $13 \cdot 1$ & $17 \cdot 0$ \\
\hline
\end{tabular}




\section{Discussion}

The initial cross-sectional studies of these men in the 1960s were not planned as the first phase of a longitudinal study. This increased the difficulty of several aspects of the current study, particularly in tracing the men and formulating criteria for radiological diagnosis. Consideration of the possibility of a follow-up study should be included in the design of any cross-sectional study.

About half the original sample had changed their job, either leaving the dockyard entirely or moving to supervisory posts. No records of these changes in place of employment and home address had been maintained. In addition our mortality records were not started until 1972. The tracing exercise extended over a period four times longer than that taken to re-examine the men.

Radiological diagnosis of asbestos-related pleural lesions and parenchymal fibrosis had improved during the intervening years both in the technical quality of the radiographs and the expertise of the readers. We were fortunate to obtain the same mass miniature radiography unit and type of film, as both are now obsolete, and to employ the technicians who had taken and processed the original $100-\mathrm{mm}$ films. The greatest handicap was the absence of full-size chest radiographs of the men in 1966 and 1968 as these would have allowed us to redefine the prevalence in these years. We took great pains to establish the degree of pleural thickening that would have been reported in the original $100-\mathrm{mm}$ films and applied this to the 1977 films.

Previously published results of these studies 45 show that men in groups 2,3 , and 4 had a relatively low risk of developing an asbestos-related lesion and an almost negligible risk of parenchymal fibrosis. We now assert that these risks are reduced further if the man is a non-smoker, irrespective of his age and occupational group. Our observation that all those with parenchymal change were or had been smokers differs from that of Becklake et al, ${ }^{6}$ although there remains a small but non-zero probability of a non-smoker with parenchymal change not being found in a study of this size and design.

\section{Conclusion}

We conclude that among men exposed to asbestos dust at work the risk of developing an asbestosrelated lesion is related to smoking habit in addition to the duration, intensity of exposure, and time since first exposure; smokers and ex-smokers may have a significantly higher risk than non-smokers.

This information should be useful to the occupational physicians in dockyards and other industries with similar risks from asbestos when faced with the exposed man, perhaps at a preretirement examination, who wants some estimate based on fact of the chances of developing these lesions. We also believe that it may be useful in formulating plans to use limited health-screening resources to best advantage.

We gratefully acknowledge the co-operation and encouragement received from dockyard management, trade unions, medical and nursing staff, and especially employees past and present. We also thank Chief Executive Royal Dockyards, Director General Stores and Transport (Naval), the Medical Research Council for financial support, and the MRC Pneumoconiosis Research Unit and the South-west Regional Health Authority for providing staff and technical help. Finally, we thank Dr J Hesketh for his support in screening the radiographs and undertaking clinical follow-up of patients at Portsmouth.

\section{References}

${ }^{1}$ Sheers G, Templeton AR. Effects of asbestos in dockyard workers. Br Med J 1968;3:574-7.

${ }^{2}$ Harries PG, McKenzie FAF, Sheers G, Kemp JH, Oliver TP, Wright DS. Radiological survey of men exposed to asbestos in naval dockyards. Br J Ind Med 1972;29:274-9.

${ }^{3}$ Harries PG. The effects and control of disease associated with exposure to asbestos in a naval dockyard. University of London, 1970. (MD thesis)

4 McMillan GHG, Sheers G, Pethybridge RJ. A radiological follow-up study of the effect of asbestos in dockyard workers at Devonport. J R N Med Serv 1978;64:88-104.

5 McMillan GHG, Sheers G, Pethybridge RJ. A radiologica follow-up study of the effects of asbestos in dockyard workers at Portsmouth. J R N Med Serv 1979;65:63-74

- Becklake MR, Liddell FDK, Manfreda J, McDonald JC. Radiological changes after withdrawal from asbestos exposure. Br J Ind Med 1979;36:23-8. 